\title{
The Relationship of Social Media Networking and Human Resource Recruitment: A Literature Review
}

\author{
Syarifa Hanoum ${ }^{1}$, Josua Hasiholan Munthe ${ }^{1 *}$, Prahardika Prihananto ${ }^{1}$, Aldi \\ Arhab $^{1}$, Dwika Zain Magenda ${ }^{1}$, Muhamad Ady Nugroho ${ }^{1}$, Oktavihana \\ Manalu ${ }^{1}$ \\ ${ }^{I}$ Department of Business Management, Institut Teknologi Sepuluh Nopember Surabaya
}

*Corresponding author. Email: josuamunthe.16@gmail.com

\begin{abstract}
Social media networking such as LinkedIn, Facebook, YouTube, and Instagram, have created higher possibilities for a candidate to get their career goals. Several studies have prov en that social media networking is convenient and practical for employers and job seekers. Social media networking allows job seekers to share their background to employers, including qualifications, work experience, and skills in more interestingly. Furthermore, this kind of social media helps employers to find potential candidates. Therefore, social media has benefits for the human resource recruitment process. This has also led researchers to conduct research related to the influence of social media on recruiting human resources. Research in this field has developed both in terms of quantity and terms of topic development, so that a more structured study of literature related to this field will have great benefits. This study uses the method of bibliometric analysis, including the analysis of citation and analysis co-citation for 78 articles as the study of the literature. The result shows that research in this field has developed since 2000 and showed a positive trend, especially in the last four years. Further, some new keywords appear each year, which indicates that the research in this field is more interesting to study. The research's implications and recommendations are that online recruitment helps companies get candidates in line with their needs. Online recruitment provides benefits for companies and job seekers regarding the time and cost-effectiveness of recruitment, targeting specific groups, to reach worldwide coverage.
\end{abstract}

Keywords: Social Media Networking, Human Resource Management, Literature Review, Bibliometrics, Online Recruitment.

\section{INTRODUCTION}

Human Resource Management is a way to manage the resources or labour within the company [8]. Human Resource Management created the system to maximize employee effectiveness to achieve company goals [9]. To achieve this goal, the study of human resource management will demonstrate how companies should recruit, manage, lead, develop, and evaluate human resources with quantity and quality in the optimal and professional [2]

One of the primary keys in creating the optimal human resource and professional is recruitment, training, and development, evaluation of which is traversed by the employee [5]. In general, recruitment is defined as finding and attracting qualified candidates to fill a particular position in a company [10]. However, in general, the company and the candidate will be involved in recruitment activities that can be categorized as traditional methods because it involves collecting physical documents, interviews, and physical meetings [13].

Furthermore, [16] states that the traditional recruitment method will require more effort, time, and cost than online recruitment. Employers have to advertise the job vacancies in traditional and conduct the recruitment process physically. In this case, the company should choose candidates for conventional, set the time and place of the interview, and involve outsourcing, consulting, referral, recruitment, campus, 
or selecting employees in-house, which requires cost and time.

A complicated process above, prompting the company to transform the recruitment of a more modern and practical, uses the job portal to online and social media platforms in screening and selecting candidates according to the company's needs [1]. This is evidenced by the growing popularity of social media platforms that are professional in the recruitment process [12].

From the perspective of the professional, social media allows users to update information about their expertise, such as qualifications, work experience, and skills representative [11]. One positive impact is finding a more diverse and appropriate candidate following the required qualifications. In addition, the possibility of the emergence automatically job recommendations that fit the profile of the applicants will also be an excess of job portals online [14].

Among various social media which support the recruitment process work, some research has identified LinkedIn (94\%) was found as the best platform among social media in support of human resources management, followed by Facebook (65\%), Twitter (55\%), Google Plus (18\%), YouTube (15\%), and Instagram (13\%). In addition, site-based websites such as Video share, Xing, You Peek, and Skilled Africans are also channels of recruiting famous employees in various country-specific [12]. Several previous studies also discuss the adoption process of online recruitment in human resource management strategy using bibliometrics [3, 7, 12]. In addition, previous research has discussed some of the challenges that organizations must face when implementing technology in the recruitment of [4]. However, there are significant changes in technology, and the internet affects the recruitment process online to give researchers new opportunities to investigate further. Some of them are the appearance of the recruit's platform such as LinkedIn Talent, UltiPro. In addition, in recent years an increase in users in a variety of platforms for online recruitment.

Therefore, by reviewing 78 relevant articles, the author aims to 1) Analyse the relationship between social media networking and the human resource recruitment process. 2) to analyse the developments and changes in the trend of the research on the influence of social media in human resource management over time and 3) Provide managerial implications and recommendations for the reader.

\section{LITERATURE REVIEW}

\subsection{Recruitment}

Recruitment is the process of attracting a candidate to fill a vacant position [14]. In the process, candidates require accurate information about what it is like to work in a company. At the same time, a company requires accurate information about candidates to determine candidates' suitability with company needs. Through recruitment, the company can communicate with certain parties to get potential candidates.

In the principle of The Right Man on The Right Job. The following are some of the functions of recruitment, as follows: Provide a candidate of prospective who meets the requirements, to help reduce the possibility of leaving employees who have not worked for a long time, to coordinate recruitment efforts with selection and training programs and to fulfil the company's responsibilities to create job opportunities

\subsection{Traditional and Online Recruitment}

\subsubsection{Traditional Recruitment}

This traditional method is a method that uses sources that are not supported by modern technology. Usually using external recruitment sources such as print media and image or sound media. Some of the most popular traditional recruitment methods are through media advertising and employment agency

Media advertising communicates the company's employment needs to the public through media such as newspapers, trade journals, radio, television, and billboards. Companies should seek to personally appeal to a prospective candidate, emphasizing the unique qualities of the work. Companies should tell potential employees why they should be attracted to specific jobs and organizations. The message should also indicate how the applicant should respond, apply personally by phone, by letter, or send a resume by facsimile or email.

Then, employment agencies are organizations that help companies recruit employees and help people search for work. The agent will select a candidate that suits the company's needs. This process will require a high cost and time because it requires a consultation and referral process.

\subsubsection{Online Recruitment}

Online recruiting is a modern recruitment method to help companies find a candidate to fill a position in 
the company. Online recruitment supports a fast process and can attract a wider range of talented candidates, making the hiring process more efficient and effective for employers and candidates. Online recruiting has several advantages over traditional recruiting methods. First, this method is cheaper because it uses online advertising, which requires lower costs. In addition, it is effective to get responses faster and often in greater numbers than traditional methods. The tasks of contacting candidates and processing resumes can be computerized, reducing hiring time.

Some of the online recruitment types are virtual job fairs and company career websites. A virtual job fair is an online recruitment method by which a single employer or group of employers attracts many applicants. An online job fair is held for certain groups, such as university students. The program allows students to visit virtual booths of employers and submit their resumes online 24 hours, seven days a week.

Then, a company career website is a job site on the company homepage that displays a list of available positions and providing a way for applicants to apply for certain jobs. Career websites have become popular sites for job seekers and companies. Nowadays, many companies have created career portals on their company websites, usually on the homepage, labelled careers or jobs. Clicking on the link will take the visitor to the hiring application. Through this link, people can apply for work in a job within the company if required.

\subsection{Bibliometrics}

Bibliometrics is a research method to analyse bibliographic data in articles/journals. This analysis is usually used to investigate references to scientific articles cited in a journal, map the scientific field of a journal, and classify scientific articles according to a research field. The approach used in the bibliometric analysis is the citation analysis approach to see one article cited by one other article, and the co-citation analysis approach to find two or more articles cited by one article.

The objectives of bibliometric are identifying trends and patterns of scientific growth in various disciplines, analysing the novelty, obsolescence, and distribution of scientific reference distribution, estimating productivity, publishers, authors, affiliations, countries or all disciplines and the basis for future research and avoiding repetition of research that has been researched.

\section{RESEARCH METHODOLOGY}

This research was conducted through five phases: preparation, data collection, descriptive analysis, analysis of bibliometric, and conclusion. The Vosviewer software will support the bibliometric analysis and visualization of data that have been processed. The stages are presented in Figure 1.

At the preparation phase, the author will formulate the problem through a review of the literature study. Then, the research objectives were found. At the data collection phase, the authors conducted a literature search through a database of international journals, namely Scopus. In this study, keywords were used as search base the study of literature. In the process, found as many as 382 of the literature using the keywords "Online Recruitment" and "Recruitment OR "Job" OR "Career" OR "Selection," "Professional Social Networking" and "Recruitment OR "Job" OR "Career" OR "Selection" and "Social Media Professional."

Then, the selection is made based on the publications that meet the inclusion and exclusion criteria to find relevant literature. The inclusion criteria used were that the study of literature should be discussing the topic of the use of technology and the internet in the strategy of human resource management, the process of recruitment, training, management, and evaluation. Then, the literature study should be published in journals and proceedings of the results of a conference and using the English language. While, the exclusion criteria include that a publication is not multiple, which can detect from the Digital Object Identifier. Then, the publication is not a thesis or dissertation. So, at this selection found 340 the relevant literature. Lastly, the selection is made based on the analysis of titles and abstracts. As a result, it is found that 78 of the literature is used as a reference source in this study.

Next, the descriptive analysis phase works to describe the distribution of data. The data distribution is the measurement of the central tendency and the measurement of shape. The techniques used in descriptive statistics in this study are percentages, averages, and standard deviations.

The bibliometric analysis phase is carried out through citation and co-citation analysis. The analysis of citation analysis is to measure the frequency of a publication is cited by other authors. In this analysis, 
citations are divided into two types: global citations and local citations. Then, co-citation is the relationship of co-citations between the two authors, documents, journals by comparing the co-citations of the author for all the citations they received.
The last phases are discussion and conclusion to get research implications. The method is presented in Figure 2.

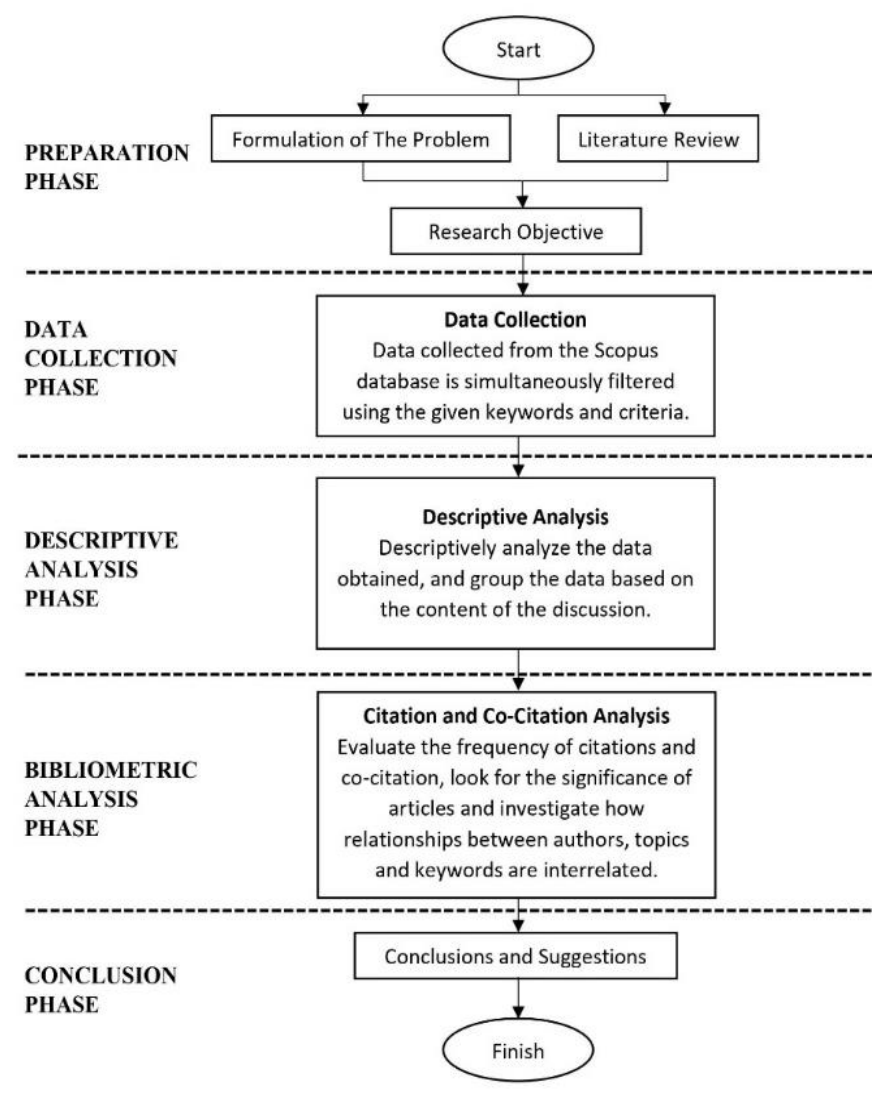

Figure 1. Flow Diagram Research

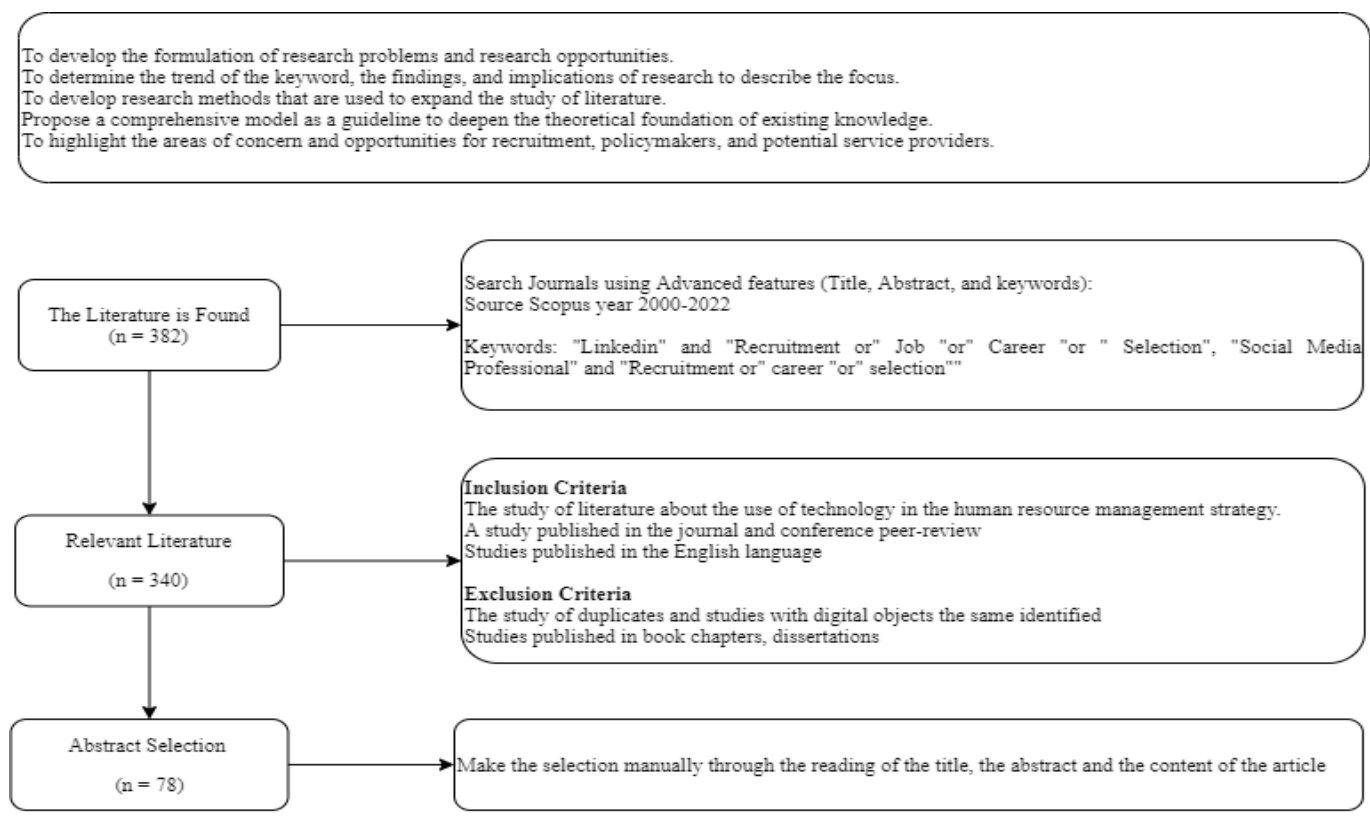

Figure 2: Step of Bibliometric Analysis 


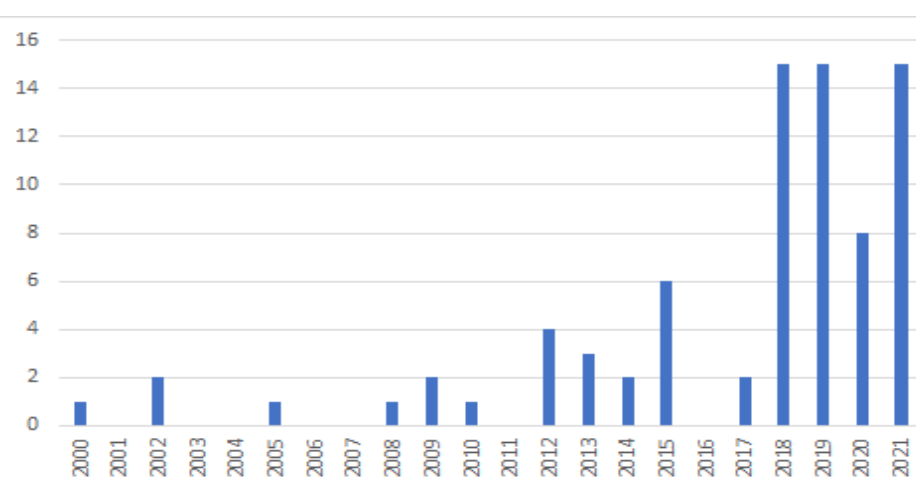

Figure 3. Production Research Article Annually

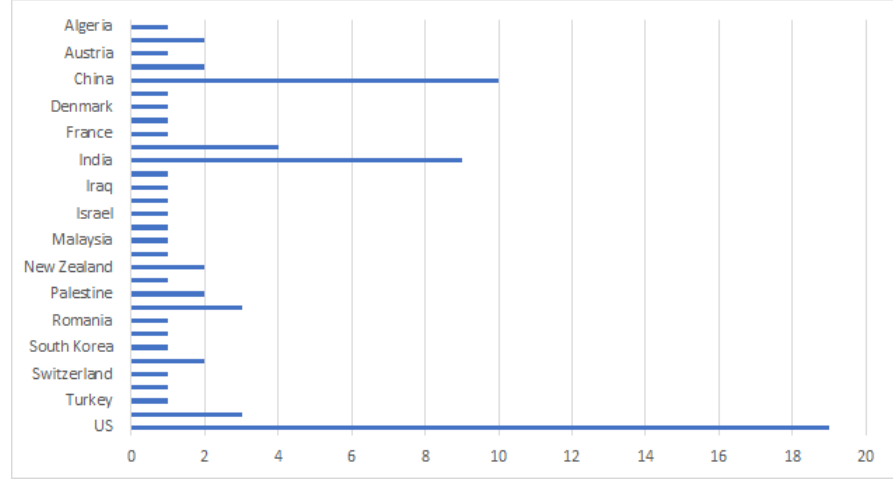

Figure 4. Distribution of Articles by Country

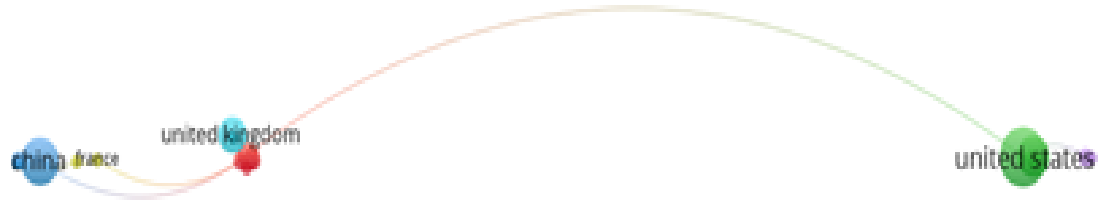

Figure 5. Country Association of Articles

\section{RESULTS}

\subsection{Descriptive Analysis}

Based descriptive analysis provides a number of publications articles per year from 2000 until 2021 related to human resource management. In Figure 3, it showed how the production of research articles annually.

Based on Figure 3, the research on social media in human resource management has existed since 2000 . However, there was no significant amount of research and stagnated until 2014. The increasing trend was from 2015 until 2021. However, there is a decrease in publications in certain years, such as 2016 and 2017. In 2018, 2019, and 2021 there are significant productions up to 15 publications per year. The research in this field has a positive trend from the results, especially in the last four years. Therefore, the research in this field attracts the researchers' attention.

Next is the analysis of the state's distribution which is carried out to determine which countries contribute to the research shown in the mapping affiliate areas of the country the author of the article.

In Figure 4, the chart shows how the distribution of location shows the state author's contribution to the research of most, which are the United States, by 19 articles, followed by China as ten articles and India with a total of nine articles.
Then, in Figure 5, stripes on the mapping results indicate affiliate location writers. Four countries that conduct affiliate research include the United States, China, Britain, and France. There are authors from the United States to conduct collaborative research with China, Britain, or France

\subsection{Bibliometric Analysis}

\subsubsection{Citation Analysis}

Citation analysis is to measures the frequency with which other authors cite a publication. The higher the number of citations in a study, the higher the usefulness of the research. Therefore, the analysis of citations can explain the relationship between the publication. In this analysis, citations are divided into two types: global citation and local citation. Further, local citation can be interpreted as a cite between the publication of the same scope. The citation that occurs between the 78 articles were selected in this study is called a local citation. Whereas global citation is the number of citations of a publication by other authors affiliated with Scopus as the data source. From 78 articles processed, there are five publications top local citation and global citation shown in Table 1 with the first two columns for the local citation and two columns next to the global citation.

Table 1 shows that the number of global citations is not always in line with the number of local citations. For example, in the global citation, research of the Lane t.s. (2015) ranks first in the global citation 
Table 1. 10 Publication of the top-rated based on citations and local citations global

\begin{tabular}{|c|c|c|c|}
\hline Author (year) & *Local citation & Author (year) & $* *$ Global citation \\
\hline Galanaki e. (2002) & 5 & Lane t.s. (2015) & 95 \\
\hline Lane t.s. (2015) & 2 & Galanaki e. (2002) & 76 \\
\hline Faliagka e. (2012) & 2 & Faliagka e. (2012) & 59 \\
\hline Melanthiou y. (2015) & 2 & Boast t.c. (2020) & 58 \\
\hline Faliagka e. (2014) & 2 & Melanthiou y. (2015) & 47 \\
\hline
\end{tabular}

but not also ranks first in the local citation. On a local citation can be known through the table that the research conducted by Galanaki e. (2002) ranks first in the number of local citations but does not also occupy the first in a global citation.

It was found that Galanaki e. (2002) has the highest local citation and ranked second in the global citation, which is as much as five citations in a local citation and 78 citations in a global citation. Then, Lane t.s. (2015), which occupies the first position in the excerpt global, also ranked two local citations, which is as much as 95 citations in the global citation and two citations in a local citation.

\subsubsection{Visualization of Citation Network}

The selected data were processed by the software VOSviewer to obtain the visualization of the network of citations of 78 articles. The visualization shows nodes and a series of lines that will show how the citations are related between articles. Software VOSviewer will automatically recognize a group or cluster which are marked with different colour. However, if there are articles with no relationship to the citation locally (links $=0$ ), they will automatically not be displayed. The cluster will be grouped based on the existing colour and are generally located adjacent to each other. Figure 6 shows the results of the mapping network of citations that has been entered.

Figure 6 shows that from the 78 articles processed by VOSviewer, only 26 articles have relationship topics, and the rest do not have. It shows that each node has a colour code that varies according to cluster articles in which there are five clusters of citations in the data entered. The fifth colour code is red, green, blue, yellow, and purple. Each colour code is our analysis on some of the points below:

\section{1) Red Colour}

The red colour is the colour that appears most on the results of the mapping of the citation. Many authors raised the same topic so that the cluster research with the colour red has a reasonably large portion on the results of the mapping. The author of the earliest publications in this cluster is Assunção M.C.F and Barros 2019. This shows that all nodes are directly or not directly related to the research conducted by Assunção M.C.F and Barros, as seen in Figure 6. The main discussion in the cluster is the influence of the profile applicants against the election platform of online recruitment.

2) Green Colour

The green colour is the second colour that appears on the results of the citation mapping, where there are six nodes. Some authors take the topic of discussion that have some similarities and are successfully identified by the author. In the green cluster, the earliest publication is Armin J, 2015. Key topics and concerns in this cluster are the literature on online recruitment in the health field.

3) Blue, Purple, and Yellow Colour

The next cluster is blue, purple, and yellow, which has one node, as shown by Figure 6 . Further, node

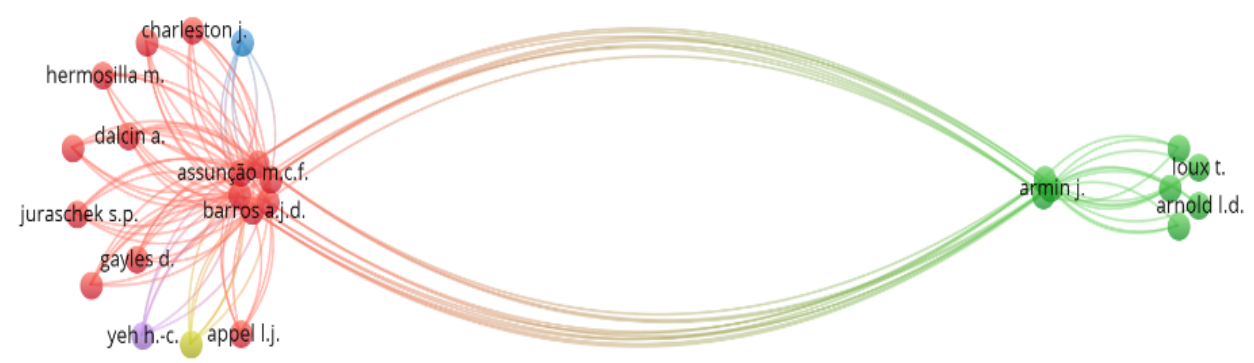

Figure 6. Citations Network Map 
blue is an article written by White K. 2018. In the code, the colour of this research topic is dominated by the difference in recruitment strategy through online advertising recruitment and traditional.

\subsubsection{Co-Citation Analysis}

Co-citation is the relationship of co-citations between the two authors, documents, journals by comparing the co-citation of the author for all the citations they received. Further, the authors attempt to identify the relationship between the articles contained in the data that have been selected previously. Cocitation analysis was performed using the software VOSviewer and utilized the features of co-citation. These features may indicate the mapping of the citations between documents into data comparison. So, if there are articles with a relationship of cocitation with another article, the article will have connecting lines that show that the article is cited simultaneously. Figure 7 show the results of the cocitation from 78 articles collected and processed using the VOSviewer. Figure 7 shows nodes with a description of the name of the author adjacent and marked with the code of a particular colour. A node with the same colour as a research group or cluster of research has similarities in the topic matter.

Based on the mapping of co-citation in Figure 7, five different colour codes show five research clusters from data entered. The analysis of each cluster to see the correlation inter research. The colour code is green, yellow, purple, blue, and red. Each colour code is our analysis on some of the points below:

\section{1) Green Colour}

The green colour is the most frequent colour that appears on the mapping of co-citation the author has done. Many authors raised the same topic so that the cluster research with the green colour has a reasonably large portion on the results of the mapping. One of the writers on this cluster was Xiong H., who raised the topic of "Methods of a certain approach to get the fit between workers with job descriptions at the recruitment stage".
Then, Faliagka E. raised "Online consistent ranking on e-recruitment: Seeking the truth behind a well-formed CV". Therefore, this cluster focuses on getting the fit and appropriate human at the time of recruitment.

2) Yellow Colour

The yellow colour is the second colour that frequently appears on the results of the mapping of co-citation. Some authors take the topic of discussion that have some similarities. One of the writers is Javed F., publicize "Developing and deploying a large-scale employer-namenormalization system for online recruitment". Next, Jacob F. discussed "Carotene: A job title classification system for the online recruitment domain". Therefore, the research topic of this cluster is the development of a new technology system to help the process of online recruitment.

3) Blue Colour

The blue colour is a cluster of research that frequently appears to be the author of the analysis of co-citation mapping with VOSviewer. One of the authors' mapping results is Zeebaree S.R.M. with the research topic "Design and Implementation of Electronic Enterprise University Human Resource Management System". Then, Wang W. with the research topic "Learning Effective Representations for PersonJob Fit by Feature Fusion". Both authors mentioned at the top of the lift research topics that have similarities in applying technology in the implementation of human resource management.

4) Red Colour

Various journals have been published on this cluster has a complex relationship. This is evidenced by the number of connecting lines (links) between nodes are coloured with red. Some author is Kim H.S. with the research topic "Obtaining quality data using behavioural measures of impulsivity in gambling research with Amazon's Mechanical". Then, Turk and Liu H with the research topic "Beyond Matching: Modelling Two-Sided Multi-Behavioural
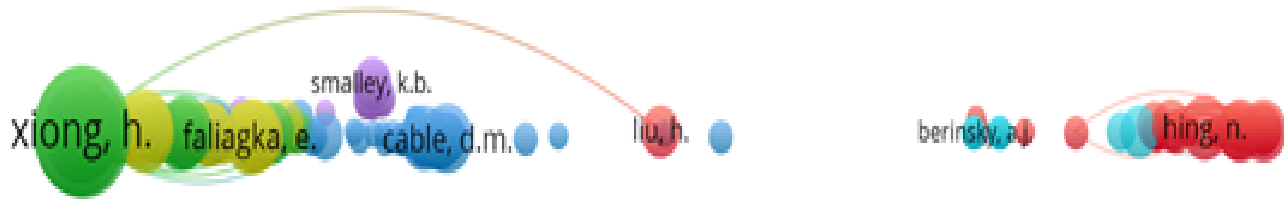

Figure 7. Co-Citation Network Map 
Sequences for Dynamic Person-Job Fit". The two authors of the journal that the authors mentioned above have a common topic of research on analysing behavioural aspects of the company's human resources.

5) Purple colour

Cluster research with the colour purple is a cluster of a recent study that the authors will discuss. Not many researchers raised the topic of discussion is the focus of the research is indicated by the number of nodes that a bit of and focused on one single point only. The author identified in the cluster, such as the Huang J. that raised the topic of "The effects of person-organization fit objective feedback and subjective perception on organizational attractiveness in online recruitment". Next, Bryant Smalley K. raised the topic of "Recruiting rural and urban LGBT populations online: Differences in participant characteristics between email and craigslist approaches". The second author is attempting to take the topic of research on the subjective perception at the stage of recruitment.

\subsection{Research Trends Analysis}

Trend analysis of this study, the authors, use the feature co-occurrence on the VOSviewer to find out the keywords which frequently appear in the research, both on the title and the abstract of the article that we choose. Below is the result of the mapping of feature co-occurrence that we have done.

The diverse keyword that appears on the mapping results by utilizing co-occurrence features is classified by the year of publication of the article. The analysis is to determine the keywords that frequently appear in the given time range and show the trend of the research that has taken place and is ongoing.

The analysis period aims to show the mapping and level of data scattered in the analysed years. From the division of the period, the authors perform an analysis to determine what keyword often appears in years of the publication specified. For that, we divide the range of years of the publication into two periods:

1. Period I (2012-2016)

The first period of our analysis is between 2012 to 2016. In this period, several main keywords appear and are distinguished by the colour group shown in Figure 8. Because the first period is from 2012 to 2016 , we can focus on the node with the purple to green colour group. In this period, a few keywords indicate the research topic in the year of the publication. Some topics appear as the trend of the research, including the applicant, directional, competencies, personnel selection, surveys, online recruitment, human resources management, and information system.

2. Period II (2017-2021)

The second period analysed in the range of 2017 to 2021. Several main keywords appear and are distinguished by the green to yellow colour group in Figure 8. Because the second period is from 2017 to 2021. In this period, some keywords are same with the first period. It shows that the topic has the trend research that is positive and interesting to study every year. However, there is some new topic that started popping up. Some of the topics to be trends in the year of this publication are semantics, convolution, personnel

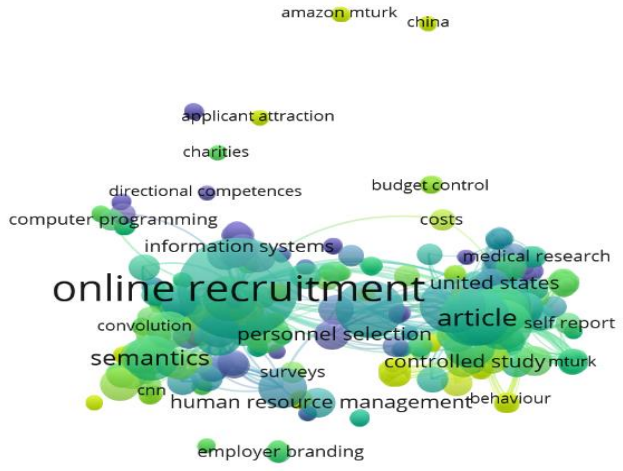

Figure 8. Keyword Map 
selection, online recruitment, computer programming, behaviour, controlled study, and branding.

\section{DISCUSSION}

This section will discuss the analysis and discussion of the research conducted to bibliometric citation analysis, co-citation, and research trend analysis. The authors collect information such as similarities in research topics, correlations from each journal, a significant increase in the number of studies related to human resources. The author analyses the findings and implementation in human resource management for theoretical implications and managerial implications in the discussion section.

In theoretical implications, the results of this study have added insight into research trends in human resource management. Then, it shows that literature review as a form of non-field work can be an alternative research method for academic research that can provide comprehensive results.

In addition, this study found that Lane t.s. (2015); Galanaki e. (2002); Assunção M.C.F and Barros 2019 dominate the topic of this research. Thus, the managerial implications that can be taken are: First, the online recruitment method makes it easy for companies to get candidates in line with their needs. Second, online recruitment provides benefits for companies and job seekers regarding time and costeffectiveness of recruitment, targeting specific groups, to reach worldwide coverage. In its implementation, Facebook was found to be the most effective method in advertising online recruitment with $42 \%$ points, followed by Google at $25 \%$.

Although online recruitment methods may be promising to be applied, some challenges can reduce the effectiveness of recruitment, such as candidate retention. Therefore, more specific recommendations are needed.

\section{CONCLUSION}

\subsection{Conclusion}

Based on the analysis, we conclude that research in this field has developed since the year 2000. Research on the influence of social media in human resource management showed a positive trend, especially in the last four years. This indicates that research is increasingly in to discuss. Based on data from Scopus, the United States is a country which have biggest number of author who addresses the influence of social media in human resources management, as there are 19 articles to address this topic. On identifying the number of citations, it can be concluded that the number of citations of the global is not always in line with the number of citations local. For example, global citations research of (Lane t.s., 2015) ranks first in the global quotes but not first in the local citation. In the visualization of citation bibliometric, five clusters show how the linkage of citations between articles, but only 26 articles have a relationship with a local citation. The largest cluster is red, with the earliest publication in 2019 by Assunção M.C.F and Barros. The main discussion in the cluster is about influencing applicants' profiles to select online recruitment. The co-occurrence analysis of the co-occurrence shows the number of keywords from year to year and in many studies. Not just a topic that is growing increasingly complex, but the research method is also used to experience growth. Follow the trend, then predict future research topics that appear to be more and more specific.

\subsection{Future Research Recommendations}

Recommendations are given based on the constraints and limitations of this study are as follows:

1. Perform the analysis using more than one software that can complement each other needed features, such as CitNetExplorer, Gephi, and BibExce. With the use of more than one software, it is expected to utilize the complementary feature of the analysis and produce better analysis results

2. Conduct bibliometric study that focus only on a particular country to know how research in a specific country is related each other.

3. Conduct bibliometric study by using the combined data from the various research article and journal database, such as Scopus, Web of Science, SINTA, and PubMed to get more qualified number of data set of bibliographic information.

\section{AUTHORS' CONTRIBUTIONS}

Syarifa Hanoum is the main author of this article. She is the head of research team that supports the organization of this article.

Josua Hasiholan Munthe is the corresponding and co-author of this article.

Prahardika Prihananto is the co-author of this article. He also a member of research team that supports the organization of this article.

Aldi Arhab is the co-author of this article.

Dwika Zain Magenda is the co-author of this article. 
Muhamad Ady Nugroho is the co-author of this article.

Oktavihana Manalu is the co-author of this article.

\section{ACKNOWLEDGMENTS}

This work was supported by Department of Business Management, Faculty of Creative Design and Digital Business and The Directorate of Research and Community Service, Institut Teknologi Sepuluh Nopember, Surabaya, Indonesia.

\section{REFERENCES}

[1] Boşcai, B. G. (2017). The evolution of erecruitment: the introduction of the online recruiter. In Management and Organization: Concepts, Tools and Applications. DOI: https:// doi.org/10.18515/dbem.m2017.n02.ch13

[2] Bratton, J., \& Gold, J. (2017). Green HRM and Environmental Sustainability. In Human Resource Management. DOI: https://doi.org/10.1057/978-1-137-58668-1_16

[3] Buettner, R. (2015). A systematic literature review of crowdsourcing research from a human resource management perspective. Proceedings of the Annual Hawaii International Conference on System Sciences, 2015-March. DOI: https:// doi.org/10.1109/HICSS.2015.549

[4] Cober, R. T., Brown, D. J., Keeping, L. M., \& Levy, P. E. (2004). Recruitment on the net: How do organizational website characteristics influence applicant attraction? Journal of Management, $30(5) . \quad$ DOI: https://doi.org/10.1016/j.jm.2004.03. 001

[5] Kasmir M.M., M. . (2016). Manajemen Sumber Daya Manusia (Teori dan Praktik). In Manajemen Sumber Daya Manusia (Teori dan Praktik).

[6] Ferdinand, A. (2006). Metode Penelitian Manajemen, Penerbit BP Undip.

[7] Lang, S., Laumer, S., Maier, C., \& Eckhardt, A. (2011). Drivers, challenges and consequences of E-recruiting: A literature review. SIGMIS CPR 2011 - Proceedings of the 2011 ACM SIGMIS Computer Personnel Research Conference. DOI: https://doi.org/10.1145/1982143.1982152
[8] Lawler, E. E. (2005). From human resource management to organizational effectiveness. Human Resource Management, 44(2). DOI: https://doi.org/10.1002/hrm.20059

[9] Lepak, D. P., Liao, H., Chung, Y., \& Harden, E. E. (2006). A Conceptual Review of Human Resource Management Systems in Strategic Human Resource Management Research. In Research in Personnel and Human Resources Management (Vol. 25). DOI: https://doi.org/10.1016/S0742-7301(06)25006-0

[10] Meldona. (2009). Manajemen Sumber Daya Manusia perspektif integratif. In Edisi Revisi Jakarta: Bumi Aksara.

[11] Roulin, N., \& Levashina, J. (2016). Impression management and social media profiles. In Social Media in Employee Selection and Recruitment: Theory, Practice, and Current Challenges. DOI: https://doi.org/10.1007/978-3-319-29989-1_11

[12] Ruparel, N., Dhir, A., Tandon, A., Kaur, P., \& Islam, J. U. (2020). The influence of online professional social media in human resource management: A systematic literature review. Technology in Society, 63. DOI: https://doi.org/ 10.1016/j.techsoc.2020.101335

[13] Russell-Rose, T., \& Chamberlain, J. (2016). Searching for talent: The information retrieval challenges of recruitment professionals. Business Information Review, 33(1). DOI: https://doi.org/ 10.1177/0266382116631849

[14] Schuler, R. S., \& Jackson, S. E. (1997) Manajemen Sumber Daya Manusia, Menghadapi Abad Ke-21 Jilid 1.

[15] Simamora, H. (1995). Manajemen Sumber Daya Manusia, STIE. YKPN, Yogyakarta.

[16] Sołek-Borowska, C. (2019). BENEFITS AND DISADVANTAGES OF ADOPTING VIDEO RECRUITMENT. Humanities and Social Sciences Quarterly. DOI: https://doi.org/10. 7862/rz.2019.hss.46

[17] Villeda, M., \& McCamey, R. (2019). Use of Social Networking Sites for Recruiting and Selecting in the Hiring Process. International Business Research, 12(3). DOI: https://doi.org/ 10.5539/ibr.v12n3p66 